This is an accepted author manuscript" (AAM) (also known as the "author post-print")

\title{
Cristina Costa
}

School of Education, University of Strathclyde, Glasgow, UK cristina.costa@strath.ac.uk

School of Education,

University of Strathclyde

Glasgow 


\section{Outcasts on the inside: academics reinventing themselves online}

\section{Abstract}

Recent developments in digital scholarship point out that academic practices supported by technologies may not only be transformed through the obvious process of digitisation, but also renovated through distributed knowledge networks that digital technologies enable, and the practices of openness that such networks develop. Yet, this apparent freedom for individuals to re-invent the logic of academic practice comes at a price, as it tends to clash with the conventions of a rather conservative academic world. In other words, it may still take some time until academia and the participatory web can fully identify themselves with one another as spaces of 'public intellectualism', scholarly debate and engagement.

Through a narrative inquiry approach, this research explores how academic researchers engaged in digital scholarship practices perceive the effects of their activity on their professional identity. Pierre Bourdieu's concept of habitus is used as a theoretical construct and method to capture and understand the professional trajectories of the research participants and the significance of their digital practices on their perceived academic identity. The research suggests that academics engaged in digital practices experience a disjointed sense of identity. The findings presented in this article illustrate how experiences with and on the participatory web inform a new habitus which is at odds with a habitus that is traditionally expected in academia.

\section{Keywords:}

Habitus, digital scholarship, Pierre Bourdieu, identity

\section{Introduction}

As a space where intellectualism can be developed publicly and collectively, the participatory web is starting to be regarded as a catalyst for change, especially where knowledge work is concerned. When academics recognise the potential of the web as a space of participation, their approaches to how they communicate, discuss and disseminate 
This is an accepted author manuscript" (AAM) (also known as the "author post-print")

their scholarly work is likely to start taking on different dimensions (Hall, 2011; Veletsianos and Kimmons, 2011). This becomes even more important given that the current society is increasingly influenced by an economy reliant on digital technological developments.

Digital scholarship practices are understood as scholarly work supported and enhanced by the participatory web and the movements and ideals associated with it; amongst which is the open access movement that aims to make research practice and outputs accessible to a wider world (Henry et al, 2003; Fry et al, 2009). Digital scholarship is starting a tradition of openness and transparency by placing a strong emphasis on a culture of knowledge sharing online. In this sense, the participatory web consists of communication tools, applications and environments in which knowledge networks form as a result of individuals' active participation as contributors and sharers of information. A major side-effect of academic engagement online is not only reflected in the ways their work is presented, but also how they represent and perceive themselves. The meaning of using the web for academic purposes, i.e., of 'being' and perceiving oneself as a 'digital scholar' (Weller, 2012) is epitomised by a renewed sense of professional identity among academics. This issue is worth exploring because the practices and, most importantly, the deployment of selfidentity as 'digital scholars' (see own Author anonymised for review purposes, 2014), are an emerging phenomenon within the academic community.

This research is guided by the sociology of Pierre Bourdieu, especially his conceptualisation of habitus as internalised behaviour; product of life trajectories that individuals carry with them and which, in part, are translated into the practices they transfer to and from the social spaces in which they interact. In doing so, this article explores how academic researchers engaged in digital scholarship activities perceive their professional identity as part of their academic habitus; the perceptions of a professional self that is strongly influenced, and sometimes transformed, by their participation in online knowledge networks and web spaces.

To conduct this research a narrative inquiry methodology was employed with the concept of habitus playing a vital role in the background in terms of capturing and translating the narrated experiences of practice into meaningful units of knowledge, especially those 
regarding the professional trajectories and related sense of identity of the research participants.

Considering academic identities in the current knowledge society requires attention to the growing effects of the participatory web on the academic world. How the web affects academic practice, and especially what it means in terms of professional and academic identity is central to this article. This research presents a new perspective on academic identities in connection to the digital economy and aims to inform the wider digital society debate in relation to the academic profession.

This article is organised in four sections. Following this introduction, Bourdieu's key concept of habitus is presented in tandem with literature on identities. Next, I elaborate on the methodological choices made for this study. The findings of the research are then presented. I conclude the article with a discussion of the findings in relation to the work of Bourdieu.

\section{Academic identities: a reflection of (a changing) habitus}

The conceptualisation of habitus is a result of Bourdieu's attempt to overcome the dichotomy between structure and agency whilst acknowledging the external and historical factors that condition, restrict and/or promote change.

The concept of habitus, as a socially embodied system of individual and collective dispositions made visible through social agents' practices, is history that produces more history (Bourdieu, 1990, p. 54). However, habitus is more than accumulated experience or automated repetition of actions; it consists of a complex social process in which individual and collective ever-structuring dispositions converge or diverge to form and justify individuals' perspectives, values, actions and social positions, i.e., their embodied cultural capital. 
This is an accepted author manuscript" (AAM) (also known as the "author post-print")

Identity, as a product of socio-cultural, historical and political contexts (Markus and Nurius, 1986; Jenkins, 2008), is constantly being transformed by the combination of individualss experiences (Slay and Smith, 2011) and their personal traits (Cote, 1996). Wacquant (2013) contends that individual habitus - 'the idiosyncratic product of a singular social trajectory and set of life experiences' (p. 2) - may or may not contrast with the collective habitus of the social groups and institutions with which an individual is affiliated. Every field of action has its set of rules and conventions that help define it as a social space. This may agree or disagree with individual habitus and subsequently an individual's sense and perception of identity. What habitus does is to communicate the dialectics between structure and agency, between the object and the subject, through a dispositional theory of action and reflexivity.

Looking at the context of this research, in general, academia is known for featuring a set of durable dispositions that aim to ensure the reproduction of their symbolic power, i.e., their reputation and status quo. This is especially visible in the communication and dissemination of research through traditional channels of intellectual discourse, such as academic publications in toll-access journals because of their long established prestige (Northcott and Linacre, 2010; Burdick and Willis, 2011). Although the participatory web provides very effective channels of communicating knowledge and achieving influence, its impact is more notorious outside academia (Wilkinson et al, 2003). Higher Education institutions, as formal sites of knowledge production, are often more hesitant to depart from established norms (Harley et al, 2010) or recognise disruptive practices (Priem and Hemminger, 2010) because of their long tradition and reputation. Through accountability measures of academic performance that rely heavily on conventional metrics of knowledge production (Talib, 2001; Wellington and Torgeson, 2005; Northcott and Linacre, 2010; Miller et al, 2011) (e.g.: number of publications and citations, type of academic journals, etc.), academia, as a field of social relations, aims to reproduce a habitus that allegedly gives stability to the institution. At the same time, however, it is increasingly incongruent with more contemporary communication practices supported by the use of digital technologies and, especially, the participatory web (Qualman, 2010). Such is the case of academic blogs as a space for public discourse, knowledge networks as sites of influence and public debate. 
Although academia strives to maintain its structure, scholarly work is undergoing a slow process of transformation (Pearce et al, 2010), as an effect of 'outside' practices. Weller (2011) revisits scholarship in the context of the digital society and puts forward three features that are starting to characterise new scholarly practices: (1) digital, (2) networked, and (3) open (p.5). With the widespread use of the web, academics are given access to ' $a$ growing body of research data and sophisticated research tools and services' (Conole, 2012, p.16). The opportunities to retrieve and contribute to a living, dynamic, and evolving knowledge database are multiple. The participatory web provides academics with a new conduit for the dissemination and storage of research in an environment where different publics can converge. Academics are enabled to participate in online communities and networks that not only link them to their research interests, but can also connect them to new research and collaboration opportunities. In this vein, the participatory web introduces new practices, and challenges the norms of rather stable structures on which academia has established its practice, built its identity, and consequently its policies of power (Schneckenberg, 2009). 'Being' a digital scholar thus implies a cultural change (Becher, 1989; Cronin, 2003; Fry, 2004; Kemp \& Jones, 2007; Whitely, 1998, as digital scholarship calls for a distinctive set of practices that aim to give scholarly activity a post-modern touch.

The more a social field succeeds in establishing itself as habitus the more successful it is in forming and maintaining its structure. This, in return, assumes the individual's identification with the institution, , by reconciling the social agent's practices with the social structure of the institution's norms. , Habitus is often understood in the literature as a mechanism of reproduction of practices conveyed through a sense of experiential continuum (see, for example, King, 2000). However, habitus presents a more complex nature; as the 'justification' of agency, habitus is not an innate or intact set of dispositions (Bourdieu, 1977). On the contrary, in representing the social trajectory of an individual, habitus has the ability to change through the assimilation of new dispositions; the result of the individual being exposed to different realities and getting involved in new practices. Hence, an individual habitus does not necessarily translate into the habitus that the academic field tries to cultivate. It is this dissonance between institutional and individual practices that give habitus its fluidity. 
This is an accepted author manuscript" (AAM) (also known as the "author post-print")

Just like habitus, professional identity is not a static concept, but one that rather evolves, according to 'work role changes' (Ibarra, 1999, p. 765) and personal and social meanings individuals attribute to it. One's sense of self can also be shaped by one's self-conception (Ibarra, 1999) and self-interest (du Gay, 2007), i.e., who individuals think they are and what they would like to become. Hence, professional identity can be seen as a social construction (Jenkins, 2008) that takes into account an individual's role, professional structures and the wider contexts in which they interact.

Slay and Smith (2011) posit that professional identities are:

- Social(ised) (individuals are socialised into the meanings of a given profession)

- Changeable (individuals adjust and adapt their professional self to different roles and jobs)

- Modelled (individuals' work experiences and narratives of life help construct one's perceptions of the self and thus determine priorities and directions)

Professional identity can thus be understood as both an act of perception and of being perceived (Bourdieu, 1991) in a given field of action. Although an individual's practice can work in conformity with the field, through the tacit acceptance of its norms, the dispositions the individual brings to the field can also contrast with the recognised order. Habitus can work as much as a form of adaptation to the field as it can divide the field of practice. This has an impact on individuals' identification with the social field. Moreover, it tends to culminate in the recognition or misrecognition of the practitioner; of the alignment (or misalignment) of self-identity with the field's identity.

The concepts of recognition and misrecognition were often used by Bourdieu to convey perspectives of social classification, position and legitimacy, i.e., instances of symbolic capital that aim to preserve or subvert the social structure. The acquisition of such symbols as embodied habitus determines the inclusion or exclusion of the individual in the social field to which such symbols belong. Acts of recognition thus imply that both social agents and social structures share 'identical categories of perception and appreciation' (Bourdieu, 1998a, p.100), whether acts of misrecognition indicate a clash between the practices and habitus that characterise and distinguish the two parties. 
In the context of this study, habitus is used as a tool to capture and understand research participants' sense of identity within the contexts and constraints in which their scholarly work takes place. The next section will explain the context of the research and how the study was conducted.

\section{The study}

Narrative inquiry - the entwined process of elicited story-telling and reflection - assumes that social lives are woven from a personal and 'experiential continuum' (Dewey, 1934) enveloped in a given social, cultural, political and economic context. This research employs a narrative inquiry methodology as a form of meaning making to capture the experiential process of academic researchers who are advocators and active users of the participatory web within the context of their research practice.

Although narrative inquiry has often been questioned for its alleged subjectivity, given that it relies on research participants' own conceptions of reality, it has also been praised for being a tool of empowerment and/or self-improvement that is perhaps less explicit in other methodologies (Riessman, 2003; 2007). In wanting to access social realities through personal accounts I dwelled on the subjectivity debate: how could I devise a process through which I could collect, understand and interpret the professional trajectories of the research participants, i.e., their academic habitus, via their personal accounts within the limited timescale of the project?

On the issue of subjectivity, Conle $(2001 ; 2010)$ suggests observing the Habermasian principles of communicative action as they can provide narrative inquiry with the desired levels of research reliability. Considering narrative inquiry as communicative action means challenging the narrator about the truth being told through their ability to truthfully account for their state of mind, emotions and motives in producing a coherent narrative. Narrative inquiry thus becomes a process which, through different iterations, aims to establish a common understanding of the experiences narrated:

The goal of coming to an understanding [Verständigung] is to bring about an agreement [Einverständnis] that terminates in the 
This is an accepted author manuscript" (AAM) (also known as the "author post-print")

intersubjective mutuality of reciprocal understanding, shared knowledge, mutual trust, and accord with one another. (Habermas, 1979, p.3)

That is not to say that the mutual understanding of the narratives told is automatically translated into interpretation of the phenomenon being researched. The conscious application of communicative action to narrative inquiry will rather result in the intersubjective rationality of the research. In other words, sharing a common understanding with my interlocutors (research participants) meant recognising the meaning they ascribed to their narratives before I submitted those understandings to the interpretative process, i.e, before I tried to grasp why they represented their professional world in the ways they did.

In order to achieve the intersubjective understanding of the narratives I used digital technologies as a contemporary conduit of communication that can support, but which cannot on its own (re)produce the principles of communicative action. I used skype to interview the research participants and record their narratives of practices. I also made use of closed blogposts to share my understanding of their narratives with them as a form of providing them with an opportunity to confirm, enhance and/or rectify their accounts. Further collection of data was conducted via email, as a form of eliciting short, written reflections of their practice in relation to the topic under research. The use of different online tools to record participants' narratives enabled me to sustain the dialogue with the research participants during an extended period of time, thus allowing me to cross check the constancy of their accounts on the different platforms in which we interacted.

Research participants were recruited following a purposive sampling technique, in order to access 'information-rich cases for study in depth' (Patton 1990, p. 169). Criteria were thus defined to select participants deemed representative of the phenomenon this research aims to study, i.e, digital scholarship (Topp, Barker, and Degenhardt 2004). This meant that research participants:

1. were active researchers in an academic setting, that is, they held research contracts in Higher Education institutions.

2. were active users of the participatory web as part of their professional activity

3. had a web presence, that is, their digital footprint was accessible online. 
The empirical work consisted of eleven in-depth interviews with active researchers associated with Higher Education institutions in the UK, New Zeeland and South Africa. Of the eleven interviews, ten were used, because one of the research participants did not fully meet the research criteria outlined for the study.

The research did not limit research participants to a country, disciplinary background, gender or age, because the focus of the research was not on these aspects, but rather on the habitus participants developed on the participatory web as a field that they all had in common. This can arguably be the greatest weakness of this research. Yet, this particular focus enabled me to locate research participants' voices within the context of their digital scholarly work, given that such practices are still emergent in academia and therefore atypical of any given disciplinary context.

The study followed an iterative process to collect and analyse the narratives of the research participants. A first pass of narrative interpretation was written up as closed blog posts and shared with the participant-narrators for their commentary and approval. A further six month interaction with a selected number of research participants was conducted through email to deepen my understanding of their perceptions of professional identity. Each interview started with a generic question about each participant's professional background and "history of practice" as a form of positioning the participant within her/his narrative of experience and professional activity. All interviews followed a spontaneous pattern of conversation as a form of providing the narrators with ownership of their narratives of practice. However three themes were used to guide the personal narratives as a form of identifying research participants' academic habitus: (1) dissemination of research and knowledge, (2) collaboration; and (3) professional identity. These themes helped create incisive narratives of practice, thus allowing me to explore how research participants' professional identities are presented in both the contexts of a digital society and the institutions with which they are associated.

I also kept a research diary throughout the entire research process, as a form of jotting down research participants' reactions to our interactions and my own thoughts about the research process and the experience of conducting this research. Once all the research data 
This is an accepted author manuscript" (AAM) (also known as the "author post-print")

was collected and transcribed, I engaged in a process of content analysis from which I tried to identify themes related to professional identity and research participants' sense of belonging and/or displacement in relation to their own online practices.

Using narrative inquiry, I was able to trace research participants' experiences through the extraordinary shifts in academic practices caused by the exponential growth of the web, and capture how research participants deployed their professional identity in light of their newly acquired academic habitus. Bourdieu too made use of life narratives (Reed-Danahay, 2005, p.4) to explore and contrast the lived experiences within the contexts in which these were developed. Revealing the power structures of the social contexts in which personal narratives developed was central to his studies (Bourdieu, 1998b). For this research, I build on the work of Hooley (2009) who uses the reflexive sociology of Bourdieu in narrative inquiry. In doing so, the concept of habitus is "read in association with the narratives produced" (ibid, 183) and the themes identified in order to get an understanding of how research participants' online practices inform and/or transform the perceptions they have of their own professional identity.

Following Bourdieu's work (1989) - who throughout his career tried to reconcile practice and theory as interdependent entities - this research applies the concept of habitus as both and object and means of inquiry (Bourdeu, 1999; Atkin, 2000; Reay, 2004; Wacquant 2013). In doing so, the concept of habitus was implicitly used to elicit the narration of career related events and practices in a chronological order leading up to participants' current experiences with the participatory web for professional purposes. The result was research participants' narrated reflections of the development of their own digital scholarly practices. Renditions of how these practices are recognised or misrecognised by their academic peers were very prominent in their accounts.

\section{Findings}

For this research, the accounts provided by the research participants are read as narrations of the self and (professional) identity. Overall, the research narratives conveyed a strong sense of displacement between research participants' professional practice and their 
personal and social trajectories as individuals and scholars attracted by current digital technological developments that promise to reinvent knowledge work. The result was a collective narrative of disjointed identities. This section accounts for the research participants' perceptions of their own practice and where it places them in terms of professional identity. The Bourdieuian lens is applied to illuminate the narratives and explain the implications of participants' online and networked practices on the (re)presentation of their professional 'self(ves)'.

\section{Deviant trajectories: reinvention of the self}

The research analysis indicated a narrative thread that cut across most research narratives gathered for this project. It focused of the participants' circumstances of life that informed their career paths, and most likely challenged, and often shaped, their approach to practice, and consequently their professional identity. Research Participants often mentioned a "turning point" in their lives and careers that seem to have provided them with flexible approaches to practice and their careers in general, and none the least their sense of professional identity. As Ibarra (1999) asserts professional identity is a dynamic concept that evolves with changes of own's professional journeys. The reported turning point was different in each narrative. Yet, it raised awareness of their tendency to embrace change and to be flexible in their working practices. Research participants reported about:

- moving from industry or practice into academia, as was the case of Anne, Heidi, and Luke;

- wishing to refocus their career from research into teaching, and thus carry out educational research as opposed to applied research, as represented in Hector's and Luke's narratives;

- changing countries (John and Lucy);

- being embedded in a different team in a different country as part of a visiting fellowship (Maria) or,

- going through institutional changes and innovations (Lucy and Richard). 
This is an accepted author manuscript" (AAM) (also known as the "author post-print")

Research participants' narratives also outlined their strong support for the participatory web as an environment where academic researchers can exercise their creative and innovative spirit. On the web research participants can find and congregate with other scholars who share similar professional values independently of their geographic location:

(...) extended network and being able to share has been the big change in research for me (Richard)

The fostering of collaborative links, the sharing of experiences, and collective participation in open spaces are activities that partially summarise the ways in which research participants wish, and often do, conduct their research practice. Endorsement of and participation in the Open Access Movement became a pronounced example of such approaches:

I think open access - that's the way it should be to me - we do all this research and then put it into a journal that 200 people read, and I'm not interested in that, if I'm going to do something I want as many people as possible to read it. (Luke)

I made a decision a couple of months ago that whatever publications I do that I follow T. A.'s lead and only publish in open access journals, and that has huge implications for me, because there aren't many credible midwifery or nursing journals in the open access environment. (Lucy)

I want to change [my scholarly practice], because the open journals and the open form... is where knowledge is moving. (Maria)

Research participants' aspirations to transfer their ideals of digital scholarship to the institutional structures more often than not result in conflict with the rules imposed by the institution. These struggles do not deal so much with the potential of the participatory web in creating spaces for networking as they do in developing new forms of communication and dissemination of research outputs, as highlighted below:

Anything that I publish in [an open access journal] ...from the University's point of view doesn't count as research activity. (...) 
I am viewed - and this phrase has been used - I am viewed as a problem. (Hector)

This is due to the fact that collaboration as part of the research process is not a regulated research activity. Dissemination of research, however, has a long tradition. In the case of this research, the publication of research in academic journals with established reputations, no longer meets the expectations of those who make use of the participatory web as a new conduit of knowledge communication. Research participants' are avid proponents of the Open Access Movement; the idea of unrestricted online access to peer-reviewed scholarly research. They want to make their research accessible to a wider audience, they want to establish dialogues as part of their work, and they want to make a difference with and through the participatory web supported approaches they bring to academia:

I think we're in a different kind of researcher's generation ... imagine the hippies in the 70s. We're a group of people who think about these kind of things [digital Scholarship] seriously, so we can make the difference. (Maria)

Access to research participants' nonlinear paths provided the research analysis with knowledge of their historical habitus and accounts of how they dealt with change in a flexible way. As pointed at by Slay and Smith (2011) that professional identity is a process of adaptation that leads to the redefinition of the self in relation to the changes they embrace in their professional world. Research participants' narratives revealed that change has been a constant in their professional trajectories, thus leading to the understanding that they bring a rich set of dispositions from their past experiences that allow them not only to adapt to new situations but also question them. Bourdieu understood habitus as both personal traits and social trajectories (Bourdieu, 1991) generative of a system of dispositions that is translated in the way individuals act in or react to a field. He also explored the notion of 'deviant trajectories' (Bourdieu, 1998b) as a form of transforming the field by challenging the power dynamics present therein. The participatory web as a tool bridging the outside world with scholarly practice encourages deviant trajectories in that it stimulates the development of new approaches to scholarship and related epistemologies of practice. Bourdieu has interpreted 'deviant trajectories' as a form of distinction. In the context of this research, however, such deviations to established practices do not yet seem to result in 
This is an accepted author manuscript" (AAM) (also known as the "author post-print")

symbolic power able to transform collective practice; it rather seems to translate into the misrecognition of research participants' scholarly activities with the participatory web.

Even though research participants are quick to adjust their scholarly practice to the imminent changes of the wider context in which they are placed, i.e., the digital economy, their symbolic position in the field determines the effectiveness of their efforts in bringing digital practices to academia. This consequently has an impact on how they perceive themselves and are perceived professionally. The next section will explore how the adoption of digital scholarship practices and beliefs shapes research participants' sense of professional identity

Professional identities reflected: the effects of the participatory web on academic practice

Research participants shared the perception that being active users of the participatory web allowed them to be seen as someone who is different in their area of practice. The quote-example provided below illustrates this perception of the self well:

In terms of doing - using social media - you do see yourself as a bit more radical (...) someone who's got a bit more forward thinking in some respects than a lot of other academics that you meet. (Alex)

Professional identity as a form of self-conception (Ibarra, 1999) is research participants' way of distinguishing themselves from their immediate peers. It is also a form of declaring their own interests (du Gay, 2007). Research participants view themselves not only as deviant practitioners, but also and above all as innovators who are embracing new practices; a fact that sets them apart from the majority of their academic peers. What is interesting to note here is that the perception of the self is classified in relation to the 'others' who follow a different approach. Research participants were very vocal in expressing this perception as a crucial aspect of differentiation:

When you start using social media... you sort of redefine yourself from somebody who doesn't know anything about it. (Alex)

I'm definitely someone who's breaking new ground (...) in terms of doing research in a different way. The way that I use 
technology is very much a defining difference between colleagues and I. (Luke)

The use of digital technology as part of their scholarship activity confers a sense of distinction that confirms their perception as pioneers of digital scholarship. Such practices set research participants apart from the 'mainstream' scholars and allow them to translate such perceptions into a renewed sense of professional identity as 'digital scholars'. However, in the background of such perceptions is the awareness of how they are perceived by those about whom they report as lagging behind in the adoption of technology for scholarly work. i.e., their immediate colleagues.

Identity as a social construction (Jenkins, 2008) is a combination of self-perception and of being perceived. How others acknowledge or fail to acknowledge one's practice is an act of recognition and/or misrecognition that confirms or discards one's practice as valid, and worthwhile, in a given field. Research participants elaborate on how they are perceived by their academic peers and, by default, academia:

I know how others see me, they think I'm insane. They do look at me as some sort of eccentric, techie geek groupie type thing. (Heidi)

If you were to take an average across the university I would be at one extreme end of that in terms of social media use, most people are basically non-users. (Hector)

Participants' adoption of the participatory web as part of their scholarly has created a new sense of identity which, as stated in the quotes above, is not shared by their immediate colleagues. However, it is shared by their online peers:

I've got a global network of people that are interested in working broader. (Heidi)

I've got an attitude that's quite different from many of my immediate colleagues - let's put it that way - so having this on my network with people who don't feel that different from me, is an extremely important means of external validation. (Hector) 
This is an accepted author manuscript" (AAM) (also known as the "author post-print")

The narratives of experience featured in this study illustrate that research participants' practices set them apart from the traditional academic. Such competitive perceptions of how research participants' digital practices are viewed and acknowledged, or not, by two distinctive fields generate an internal conflict regarding the legitimation of their approach. This, in return, impacts on their perception of professional identity. In the context of this study, research participants are positioned between these two opposed worlds: the participatory web that supports an informal intellectual sphere and academia that provides a formal structure in which academic work is validated. Research participants' adoption of the participatory web as part of their scholarly work encourages them to question the academic order by re-defining what they do and who they are professionally. By the same token, their digital scholarly practices lead others (their peers) to re-consider how they view them within academia's structure.

\section{Outcasts on the inside: sense of isolation}

As seen above, participants in this study see their use of the participatory web in the context of their scholarly practice as a distinguishing factor when compared to the majority of their colleagues. Their use of digital technology becomes a trait that sets them apart from the majority of their peers. In the context of their academic position, this distinction, i.e., their deviant trajectories of practice, creates a pronounced sense of isolation. This is emphasised in research participants' accounts:

I would probably position myself as an outcast (John).

I'm working fairly much in isolation as far as that's concerned.

Sometimes I do feel quite isolated (Hector).

Distinction and isolation are the two main themes that characterise research participants' sense of identity with regards to their digital scholarship activity in the context of their academic practice. If on the one hand, research participants' digital activity aims to provide evidence of innovation of academic work with novel approaches and tools, on the other hand it denounces the power of the academic field as an antagonist force able to generate a 
sense professional displacement through the institutional habitus that it cultivates and aims to impose:

There are very few people who get what I do. Technology has very much had an impact on setting me apart from any of my colleagues, but I think even more than that is how I think about research and how I think about scholarship as a result of using the technology. (Luke)

By participating in online environments and within distributed networks, individuals are exposed to different ways of thinking and conducting their scholarly activity. This has an effect on the way they approach practice. It also (re)defines who they feel they are, not only in relation to their practice, but also with regards to the practices their peers carry out in conformity with the field of academia. Moreover, it separates them from the colleagues who are not yet engaged in digital scholarship activities. Yet, the struggle generated by two conflicting habitus does not seem to lead to a simple re-adjustment of individuals' dispositions to the field that arguably holds the most symbolic power, i.e, academia and its formal mechanisms to validate scholarly work; it rather generates a marked differentiation of practices and approaches to scholarly work, as the participatory web also enjoys a growing reputation, not for tradition as the latter, but for innovation.

As pointed out in the literature review of this article, the use of the participatory web in scholarly environments provides an opportunity to explore new forms of scholarship (Weller, 2011; Conole, 2012). However, very few studies have looked at how the participatory web can disconnect the individual from their local work environment, because of the duality that it creates between tradition and innovation. As the participants of this study hinted at, the participatory web can have an isolating effect in that their participation online makes their approach to practice so distinctive from the practice of those who are not part of the same online networks that they no longer identify themselves with the practices carried out at their institutions. This is accrued from their changing perception of professional self as scholars making a difference in academia through the use of digital technology. This conception of the self was often reiterated in research participants' narratives. 
This is an accepted author manuscript" (AAM) (also known as the "author post-print")

The deeper research participants went into their narratives, the more pronounced was the dissonance between institutional and individual perspectives of practice and the power struggles to which research participants are subjected because of their outlook on practice. Habitus produces practices and representations of practice that are susceptible of classification (Bourdieu, 1984; 1989). Digital scholarship as an emergent practice still does not enjoy of a high rated classification, thus characterising research participants' digital practice as deviant trajectories resistant to the norms of academia.

Although research participants embody a distinctive identity, as digital scholars, they are only partially esteemed for it, because what the field of academia aspires is the establishment of a homogenous habitus, one that it can recognise at its own rather than one that questions its ordinary norm. Yet, this sense of displacement is cancelled when individuals situate their practice in the field of the participatory web which informs their changing academic habitus. An individual exists within a socially constructed space of identity and she/he is perceived according to the principles that define both the field and the individuals that share that common social space. Identity is thus translated not only into a sense of belonging (Stuart et al, 2011), but also into a form of recognition of the traits that characterise a given group (Bourdieu, 1988).

The opposition of the field of academia to deviant habitus results in a sense of displacement that seems to give prominence to individuals' divergent scholarly dispositions through perceptions of differentiation. Although this distinction might not, in the context of academia, result in the aspired merit and reputation of research participants as digital scholars, such deviant trajectories '(...) are undoubtedly one of the most important factors in the transformation of the field of power.' (Bourdieu, 1998b, p.184). This is so because the participatory web, as a social field, informally supports and absorbs participants' changing habitus as its own, thus partially compensating for what the field of academia fails to recognise. Habitus is thus more than a tool of reproduction; it can also be an instrument of change. This is notorious in how research participants' question the institutional habitus with the habitus they develop in and carry from their online knowledge networks. The space created between the oppositions of the two fields becomes the locus of research participants' sense of (disjointed) identity. 


\section{Discussion and conclusion}

Habitus, as an individual's or group's embodied system of dispositions, can match or differ from the social field, and sometimes even resist it. Individual belonging to numerous social spaces can see their habitus be aligned to or in conflict with the different fields of action in which they co-exist and their practice is contextualised and validated. Depending on the field, the result can either be a sense of recognition or misrecognition. The harmonious relationship between individuals habitus and the field in which they operates tends to translate in a sense of identification between the individual and that social space; of habitus and field becoming an indistinct social phenomenon. However, the dispositions individuals develops in one field is not necessarily absorbed by another distinctive field. The difference between the field and the habitus individuals bring to it leads to the misrecognition of practice and consequently a 'cleft habitus generating all kinds of contradictions and tensions' (Bourdieu, 2004, p.111). The ambivalence between the university world and research participants' intellectual journeys results is a disjointed sense of identity and a predisposition to symbolic revolutions.

According to their narratives of practice, research participants are caught between a habitus that leans towards digital practices and a field that prefers to follow academic traditions, i.e., they are torn between what they perceive to be innovative practices that renew the meaning to their activity and the conventional rules of academia that they see as stifling their novel approaches to scholarly work. The incongruence between habitus and field leads to a strong perception of misrecognition of digital scholarship and digital scholars inside academia. Yet, the misrecognition of digital scholarship in the field of academia is balanced with the informal recognition of such practices on the field that produces it, i.e., the participatory web. This can lead to the acknowledgment and perception of the 'self' as a digital scholar in times when academia struggles to reinvent itself in light of social, cultural, political, economic and technological developments typical of the contemporary society. Such 'critical crisis', Bourdieu alleges, are a turning point likely to transform practice and the 
This is an accepted author manuscript" (AAM) (also known as the "author post-print")

social and professional identity perceptions associated with it as structures and dispositions come into disruption (Bourdieu, 1984; 1988).

In this sense, I suggest that habitus is not necessarily always defined in relation to the field, as proposed by Adams (see 2006, p.517), but rather made apparent via a given field, as social agents' social and professional trajectories occur simultaneously across different fields. This is made obvious through the agreement or disagreement of individuals' dispositions with the structures of the social spaces in which their practices are materialised. Nonetheless, Adams (ibid) is right to assert that a field's assimilation or rejection of a individuals' dispositions - of the field imposing itself as habitus - can respectively result in a sense of belonging or disconnection with the norms of that space of practice. This then opens up space for reflection about the discrepancy between individual's habitus and the field that officially substantiates their academic practice. The difference between habitus and field can produce changes, but such changes can only be effective in so far social agents remain relevant in the field they aim to transform, i.e, hold symbolic positions that allow them to promote their habitus as field. Yet, if social agents' habitus can find recognition in another field, their changing sense of professional identity is more likely to be challenged rather than cancelled by the field that contradicts it. This opens scope for future change through the introduction of an 'outside' habitus. This is what research participants hinted at when they declared to wanting to make a difference with their digital practices.

Indeed, the participatory web is known for triggering a number of changes in social practices that have repercussions on individuals' perceptions of their professional identity. Professional identities, as a social construction, are determined by a sense of distinction, and such 'difference is asserted against what is closest, which represents the greatest threat.' (Bourdieu, 1984, p.481). In this research, the participatory web is characterised as an instrument of change, and in this sense, as both a promise and a threat to reinventing academia and its agents. These competing perceptions result in a digital divide, not in relation to the accessibility of digital technology, but rather to a shared logic of academic practice; a new mind-set (own Author anonymised for review purposes, 2014). This impacts on how individuals perceive themselves and their peers professionally as either digital 
scholars or non-digital scholars, innovators or tradition followers, of game changers or conformists. This discrepancy between field and habitus can affect how academics embracing digital scholarship perceive themselves and are perceived in the field of academia and by the social agents that interact therein. Yet, the struggle for imposing or changing the dominant habitus is not only one of reproduction, but also one of transformation of practices. Research participants want to reproduce the habitus acquired on the participatory web on the field of academia with the purpose of reforming it.

In 'Homo Academicus' (1988), Bourdieu reported about the opposition between new means of mass production and diffusion of cultural goods - at the time, typified especially by the radio and television - and the traditions shared by the Academy. Similarly to the mass media, the participatory web could also be said to trigger 'an anti-institutional mood, constituted essentially by their ambivalent relationship with the University' (ibid, p. 175) in that it disturbs the 'ordinary order'. The difference between traditional mass-media and the participatory web is however defined by whom holds the power to publish and communicate scholarly knowledge. The shift is no longer from one field to another, but from the institution to the individual. Ultimately, it is this power shift against which or for which field and habitus are respectively fighting that fragments individuals' sense of professional identity.

In conclusion, research participants featured in this research are embedded in a social space that generates atypical academic practices. Their participation on the participatory web and knowledge networks available therein endow research participants with a very different system of dispositions that prompt them to question the practices promoted in academia. This contrasting habitus impels them to break with the established order in an attempt to '(...) defend their own interests' (Bourdieu, 1988, p.175) and try to question academia with the properties that constitute the social identity they have developed online. What the opposition between routine and innovation, between academia and the participatory web as two distinctive fields, does is to denounce the monopoly of academic knowledge production with which research participants no longer identify themselves. In doing so, they aim to transform the academic field with a new logic of practice that reflects their new academic habitus, and consequently their professional identity. 
This is an accepted author manuscript" (AAM) (also known as the "author post-print")

\section{References}

Adams, M. (2006). Hybridizing Habitus and Reflexivity: Towards an Understanding of Contemporary Identity? Sociology, 40(3), 511-528. doi:10.1177/003803850663672

Atkin, C. (2000). Lifelong learning-attitudes to practice in the rural context: a study using Bourdieu's perspective of habitus. International Journal of Lifelong Education, 19(3), 253265. doi:10.1080/026013700293296

Becher, T. (1989). Academic tribes and territories: Intellectual enquiry and the cultures of disciplines (1st ed.).

Bourdieu, P. (1977). Outline of a Theory of Practice. Cambridge University Press.

Bourdieu, P. (1984). Distinction: A Social Critique of the Judgement of Taste (1 edition.). Routledge.

Bourdieu, P. (1988). Homo Academicus. Stanford University Press.

Bourdieu, P. (1989). Social Space and Symbolic Power. Sociological Theory, 7(1), 14-25.

Bourdieu, P. (1991). Language and Symbolic Power. (G. Raymond \& M. Adamson, Trans.) (Reprint edition.). Cambridge, Mass.: Harvard University Press.

Bourdieu, P. (1998a). Practical Reason: On the Theory of Action. Stanford University Press. Bourdieu, P. (1998b). The State Nobility: Elite Schools in the Field of Power. Stanford University Press

Bourdieu, P. (1999). The Weight of the World: Social Suffering in Contemporary Society. Stanford University Press.

Bourdieu, P. (2004). Science of Science and Reflexivity. Cambridge. Polity.

Burdick, A., \& Willis, H. (2011). Digital learning, digital scholarship and design thinking. Design Studies, 32(6), 546-556. doi:10.1016/j.destud.2011.07.005 
Conle, C. (2001). The Rationality of Narrative Inquiry in Research and Professional Development. European Journal of Teacher Education, 24(1), 21-33.

Conle, C. (2010). Practice and Theory of Narrative Inquiry in Education. In M. Murphy \& T. Fleming (Eds.), Habermas, critical theory and education. London: Routledge.

Conole, G. (2012). Chapter: New approaches to openness - beyond Open Educational Resources Cloudworks. Retrieved from http://cloudworks.ac.uk/cloud/view/6305

Cronin, B. (2003). Scholarly communication and epistemic cultures.

Dewey, J. (1934). Experience and education. Kappa Delta Pi.

du Gay, P. (2007). Organizing Identity: Persons and Organizations After Theory. SAGE Publications.

Fry, J. (2004). Studying the Scholarly Web: How disciplinary Culture Shapes Online Representations. Cybermetrics: International Journal of Scientometrics, Informetrics and Bibliometrics, 10(1). Retrieved from http://www.cindoc.csic.es/cybermetrics/vol10iss1.html

Fry, J., Lockyer, S., Oppenheim, C., Houghton, J., \& Rasmussen, B. (2009). Identifying benefits arising from the curation and open sharing of research data produced by UK Higher Education and research institutes. Retrieved from http://ie-repository.jisc.ac.uk/279/ Hall, R. (2011). Revealing the transformatory moment of learning technology: the place of critical social theory. Research in Learning Technology, 19(3), 273-284. doi:10.1080/21567069.2011.624996

Harley, D., Acord, S. K., Earl-Novell, S., Lawrence, S., \& King, C. J. (2010). Assessing the Future Landscape of Scholarly Communication: An Exploration of Faculty Values and Needs in Seven Disciplines, (January), 728. 
This is an accepted author manuscript" (AAM) (also known as the "author post-print")

Henkel, M. (2005). Academic Identity and Autonomy Revisited. In I. Bleiklie \& M. Henkel (Eds.), Governing Knowledge (pp. 145-165). Springer Netherlands. Retrieved from http://link.springer.com/chapter/10.1007/1-4020-3504-7_10

Henry, G., Baraniuk, R. G., \& Kelty, C. (2003, July 1). The Connexions Project: Promoting Open Sharing of Knowledge for Education. Retrieved from http://hdl.handle.net/1911/19951 Hooley, N. (2009). Narrative Life: Democratic Curriculum and Indigenous Learning. Springer. Ibarra, H. (1999). Provisional Selves: Experimenting with Image and Identity in Professional Adaptation. Administrative Science Quarterly, 44(4), 764-791. doi:10.2307/2667055 Jenkins, R. (2008). Social Identity (3rd ed.). Routledge. Kemp, B., \& Jones, C. (2007). Academic Use of Digital Resources: Disciplinary Differences and the Issue of Progression revisited. Educational Technology \& Society, 10(1), 52-60.

Kim, T. (2010). Transnational academic mobility, knowledge, and identity capital. Discourse: Studies in the Cultural Politics of Education, 31(5), 577-591. doi:10.1080/01596306.2010.516939

King, A. (2000). Thinking with Bourdieu Against Bourdieu: A 'Practical' Critique of the Habitus. Sociological Theory, 18(3), 417-433. doi:10.1111/0735-2751.00109

Miller, A. N., Taylor, S. G., \& Bedeian, A. G. (2011). Publish or perish: academic life as management faculty live it. Career Development International, 16(5), 422-445. doi:10.1108/13620431111167751

Northcott, D., \& Linacre, S. (2010). Producing Spaces for Academic Discourse: The Impact of Research Assessment Exercises and Journal Quality Rankings. Australian Accounting Review, 20(1), 38-54. doi:10.1111/j.1835-2561.2010.00079. 
Patton, M. Q. (1990). Qualitative Evaluation and Research Methods (Second Edition.). Sage Publications, Inc.

Pearce, N., Weller, M., Scanlon, E., \& Kinsley, S. (2011). Digital scholarship considered : how new technologies could transform academic work. Article. Retrieved 27 May 2011, from http://dro.dur.ac.uk/8072/

Priem, J., \& Hemminger, B. H. (2010). Scientometrics 2.0: New metrics of scholarly impact on the social Web. First Monday, 15(7). Retrieved from http://pear.accc.uic.edu/ojs/index.php/fm/article/view/2874

Qualman, E. (2010). Socialnomics: How Social Media Transforms the Way We Live and Do Business. John Wiley and Sons.

Reay, D. (2004). 'It's All Becoming a Habitus': Beyond the Habitual Use of Habitus in Educational Research. British Journal of Sociology of Education, 25(4), 431-444. doi:10.2307/4128669 Reed-Danahay, D. (2005). Locating Bourdieu. Indiana University Press.

Riessman, C. (2003). Narrative Analysis. In M. S. Lewis-Beck, A. Bryman, \& T. F. Liao (Eds.), The SAGE Encyclopedia of Social Science Research Methods (illustrated edition.). Sage Publications, Inc.

Riessman, C. (2007). Narrative Methods for the Human Sciences. Sage Publications, Inc. Schneckenberg, D. (2009). Web 2.0 and the empowerment of the knowledge worker. Journal of Knowledge Management, 13(6), 509-520. doi:10.1108/13673270910997150

Slay, H. S., \& Smith, D. A. (2011). Professional Identity Construction: Using Narrative to Understand the Negotiation of Professional and Stigmatized Cultural Identities. Human Relations, 64(1), 85-107. doi:10.1177/0018726710384290 
This is an accepted author manuscript" (AAM) (also known as the "author post-print")

Stuart, M., Lido, C., \& Morgan, J. (2011). Personal stories: how students' social and cultural life histories interact with the field of higher education. International Journal of Lifelong Education, 30(4), 489-508. doi:10.1080/02601370.2011.588463

Talib, A. A. (2001). The Continuing Behavioural Modification of Academics since the 1992 Research Assessment Exercise. Higher Education Review, 33(3), 30-46.

Veletsianos, G., \& Kimmons, R. (2012). Networked Participatory Scholarship: Emergent TechnoCultural Pressures toward Open and Digital Scholarship in Online Networks. Computers \& Education, 58(2), 766-774.

Wacquant, L. (2013). Homines in Extremis: What Fighting Scholars Teach Us about Habitus. Body \& Society, 1357034X13501348. doi:10.1177/1357034X13501348

Weller, M. (2011). The Digital Scholar: How Technology is Changing Academic Practice. Bloomsbury Publishing PLC.

Wellington, J., \& Torgerson, C. J. (2005). Writing for publication: what counts as a 'high status, eminent academic journal'? Journal of Further and Higher Education, 29(1), 35-48. doi:10.1080/03098770500037739

Wilkinson, D., Harries, G., Thelwall, M., \& Price, L. (2003). Motivations for academic web site interlinking: evidence for the Web as a novel source of information on informal scholarly communication. Journal of Information Science, 29(1), 49-56.

doi:10.1177/016555150302900105 